\title{
BLOW-UP: retratos da Cidade ${ }^{44}$
}

\section{Maria do Carmo Nino}

"Se o homem devesse chegar além do que ele apreende, para que então o céu?"

Jean - Claude Lattès

No que, a partir da percepção de uma cidade como Londres feita há quarenta anos por um cineasta italiano, podemos retirar algo sobre a experiência da cidade e seus intrincados labirintos de natureza espacial, psíquica, social e cultural que seja válida para os dias atuais?

Antonioni sempre se defendeu do fato de seu filme ser associado a um espaço urbano particular, sugerindo que a história poderia se desenrolar igualmente em outra metrópole como, por exemplo, Nova York ou Paris.

A escolha de Londres se deu pelo seu caráter exemplar do estilo de vida que viu nascer a Pop Art ainda em meados dos anos 50 com o quadro do inglês Richard Hamilton e o personagem Thomas no filme inspirou-se no fotógrafo de moda londrino David Bailey, entre outros. Enquanto a Pop Art enfatiza a busca de sua inspiração no cinema, na publicidade e nas tecnologias da sociedade de consumo substituindo a introspecção e o subjetivismo do expressionismo abstrato por temas recolhidos no meio urbano, Bailey faz parte dos artistas que renovaram o conceito fotográfico de moda vigente desde os anos trinta, influenciando - se do cinema do pós-guerra e principalmente da nouvelle vague, caracterizado por uma abordagem informal e voluntariamente jovial, baseada na relação entre fotógrafo e modelo.

A inserção no relato fílmico do ato de produzir, olhar e analisar fotografias pela personagem do artista Thomas, redobra-se naquele de realizar um filme, no fato óbvio de olhar e operar escolhas estéticas através da câmera feito pelo cineasta Antonioni, além do nosso próprio olhar de espectadores. Este estado de coisas não é de modo algum negligenciável: ele anuncia uma espécie de mise en abîme que tem como consequência a instalação de um tipo de impasse no desenvolvimento da narrativa ${ }^{45}$ através de sua estrutura

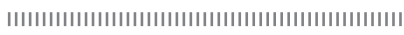

44 Texto apresentado oralmente no Encontro SOCINE, em Ouro Preto - MG, 2006.

45 Este fato está também presente, embora de outra maneira, no texto Las Babas del Diablo de Julio Cortazar que inspirou inicialmente Antonioni. Ver a esse respeito A destruição visada, in Davi Arrigucci Jr, $O$ escorpião encalacrado: a poética da destruição em Julio Cortázar, SP, Cia das Letras (1995), 2003. (p. 227-259) 
circular onde curvas de círculos excêntricos e concêntricos se recortam, promovendo a integração do outro no mesmo, além da espacialidade de característica mœbiana, ambígua entre o dentro e o fora, e relativiza as fronteiras entre realidade e ficção.

Temos então uma narrativa que se constrói de maneira orgânica, implicando-se interna e alternativamente entre três importantes instâncias: a abordagem explícita sobre a linguagem fotográfica ela mesma; sobre as razões que levam ao desenvolvimento da narração e culminam com a revelação; e o desenvolvimento temático da história, que descamba para o metafísico, principalmente no seu final, ou seja em torno de uma especulação sobre a natureza do real, debruçando-se consequentemente sobre a imprescindível relação entre subjetividade e verdade.

Senão vejamos:

Em relação à própria singularidade da linguagem fotográfica, o filme logo nas primeiras cenas nos informa imageticamente sobre um Thomas camuflado: com aparência que denota precariedade material, tomamos gradativamente consciência que ele, um fotógrafo de moda bem sucedido profissionalmente, passou a noite em um abrigo para indigentes, como parte integrante do objetivo (como saberemos posteriormente) de realizar um livro que será um retrato sobre a cidade de Londres.

Com esta dissimulação, Thomas abre espaço para a possibilidade da obtenção de imagens sobre uma metrópole enfatizada nos seus aspectos socialmente mais problemáticos, contrastante com a atmosfera de glamour que sustenta sua fama como profissional e, aspecto este que nos interessa de perto, supõe-se que estas imagens subverteriam em princípio a artificialidade e a intencionalidade da noção de pose, entre fotógrafo e modelo, requisito este que no entanto faz parte de seu cotidiano, como se vê a seguir.

Aliás, uma das sequências mais famosas do filme mostra-o em um confronto de características próximas à posse amorosa e sexual, embora não afetiva, com a modelo Veruschka, onde nos é explicitada contundentemente a grande dose de "construção da naturalidade" no universo da fotografia de moda ${ }^{46}$.

Em outra cena, desta feita com um grupo de modelos, o artificialismo é então não só assumido em todas as suas formas (cenário com detalhes geométricos, dramatização da luz, gestual teatral e afetado, maquiagem exagerada e figurino extravagante), como justamente buscado claramente enquanto efeito.

Em um terceiro momento, que se desdobram em várias sequências, agora com duas jovens pretendentes a modelos, Thomas é assediado para realizar fotos delas que serviriam para impulsionar suas carreiras. Como atesta Paulo Menezes ${ }^{47}$ é significativo o jeito como a cena da orgia do qual serão protagonistas e cuja efetivação é de caráter extra - diegético, se passa de maneira casual, não prevista e portanto não intencional. Isto

||||||||||||||||||||||||||||||||||||||||||||||||||||||||||||||

46 Esta sequência está analisada detidamente pela autora Gilda de Mello e Souza em A ideia e o figurado, SP, Duas Cidades, Ed. 34, 2005 (p. 160)

47 No livro de sua autoria À Meia-Luz - Cinema e sexualidade nos anos 70, Rio de Janeiro, Ed. 34, 2001. (p. 23) 
denota o caráter das relações típicas - embora não exclusivas - de uma cidade grande, que aproxima espacialmente seres estranhos entre si, permitindo rapidamente a instauração entre eles de um tipo de distância íntima que seria indicadora da relação amorosa, embora destituída de afeto $^{48}$.

Estes momentos citados acima acontecem principalmente no espaço fechado do estúdio, mas em contraponto a este, temos a sequência, também não intencional, do seu encontro com um casal que se abraça no espaço aberto e silencioso de um parque, situado em uma zona de renovação urbana da cidade, que será crucial para o desenvolvimento da narrativa; Thomas tira fotos dos dois ao acaso, esperançoso de ter conseguido a imagem para seu livro, que deveria terminar com algo idílico, e aí tem lugar o seu diálogo com um personagem feminino que será designado apenas como a Mulher e que porta inclusive sobre o direito ético de fotografar ou não o que bem se entenda em lugares públicos.

Tudo se passa como se Antonioni quisesse nos mostrar um retrato talvez não completo, mas certamente complexo das características, direitos, deveres, atribuições e consequências tanto éticas quanto estéticas que envolvem a prática profissional em primeira evidência, claro, da fotografia, mas também extensiva à questão da linguagem cinematográfica ou mesmo pictórica em geral.

Quanto aos elementos que vão propiciar o deslocamento da narração para um outro patamar, eles podem ser compreendidos melhor na medida em que entendemos porque o personagem Thomas nos é apresentado como um homem inserido e adaptado a seu tempo, por um lado, e também como aquele que se integra perfeitamente à sua condição de "profissional do olhar": na realidade ele é alguém que enxerga a realidade física circundante fundamentalmente a partir de sua câmera, ela é quem serve de mediadora entre ele e as coisas do mundo ele depende dela para entendê-lo e vários indícios ao longo do filme nos mostram como sua relação direta com as pessoas é problemática.

A esse respeito lembremos junto com Gilda de Mello e Souza ${ }^{49}$ de Lewis Mumford para quem a modernidade está ligada ao ciclo do vidro e este por sua vez acelera a visualização progressiva do mundo, fenômeno inclusive tipicamente urbano. A partir de pré-impressionistas como William Turner no final do século XIX, que dissolve as formas em uma luz difusa que será radicalizada posteriormente pelos Impressionistas, e mesmo pela arte abstrata e informal, a arte passa progressivamente de uma representação do real a uma reflexão sobre o real e, então, sobre a visão mesma, até à especulação sobre sua própria natureza.

O papel histórico da fotografia neste contexto será crucial, já que seu nascimento é contemttporâneo desta mudança de concepção na $\operatorname{arte}^{50}$ : o vidro da objetiva fotográfica

||||||||||||||||||||||||||||||||||||||||||||||||||||||||||||

48 Fazemos referência aqui à Proxêmica, termo cunhado por Edward T. Hall, em A Dimensão Oculta, tr. Waldéa Barcellos, SP, Martins Fontes (1971), 2005.(p.1)

49 op. cit. Ultra, p. $145-147$

50 Revista Traverses N. ${ }^{\circ} 46:$ Le verre, Paris, Ed. Centre George Pompidou, 1989. (p.88) 
duplica o olho humano, diminuindo ao máximo a distância de registro do real e o que se vê através do aparelho fotográfico é o efeito de real como se fosse visto através de um vidro, sem alteração manual da sua aparência. Este real apreendido é, portanto ambíguo, entregue aos jogos da aparência, ao mesmo tempo próximo e distante, e esta espécie de janela é uma condição ontológica da fotografia e consequentemente da câmera de filmar.

Na nossa história, a presença e o diálogo da personagem do pintor Bill, amigo e vizinho de Thomas, é sintomática desta problematização antoniana em torno da dissolução nas formas de representação clássica, e que finda por contemplar o privilégio da indeterminação da função perceptiva do sujeito em detrimento da concretude materializada pelo objeto.

O nosso personagem é inicialmente surpreendido pelo poder revelador, testemunhal e por isso mesmo incontestável das imagens tiradas no parque e em um momento de júbilo crê-se gratificado com um suplemento, um presente.

Após serem exaustivamente analisadas no seu laboratório a partir de ampliações do original, e dispostas por ele como se faz com um mapa, o que implicitamente introduz a ideia de uma percepção não ocular já que juntas as imagens abrangem uma amplitude que não é possível de ser abarcada por um ponto de vista único, elas passam, no entanto, a designar um parentesco - explícito diegéticamente por Patrícia - com os quadros de Bill, elas mobilizam o olhar e o interesse sobre algo que está além do que a observação a olho nu pode perceber e terminam por dissolver-se, impossibilitando qualquer testemunho (foram roubadas do laboratório) ou mesmo qualquer certeza. O poder de natureza indicial da fotografia entra assim em tensão inclusive com sua utilização ficcional e constitui um dos elementos fascinantes da história.

O grande mérito do filme será o de propiciar através de um roteiro sem falhas uma transformação do sentimento primeiro de euforia em uma resignação presidida pela dúvida sem que nenhuma solução possível se descortine diante dele (e de nós).

De um real que lhe era sempre oferecido sem maiores fissuras para que a dúvida se instalasse corroborando assim com o seu aspecto pragmático na primeira parte do filme, progressivamente Thomas e nós mesmos caminhamos para um questionamento acerca do imaginário e da realidade, onde os nossos sentidos, mas também incluindo aí os instrumentos dos quais nos servimos, estão bem longe de serem confiáveis.

Segundo Julio Cabrera ${ }^{51}$, em Blow - up vemos o triunfo do gênio maligno, há uma espécie de sanção paga pelo desejo de conhecimento a partir da contemplação, figura por excelência da busca arquetípica do Graal; somos golpeados junto com o fotógrafo com uma tapa de luva no rosto, pela dúvida: a realidade nada mais é do que uma construção e, ainda por cima, uma construção social ${ }^{52}$.

|||||||||||||||||||||||||||||||||||||||||||||||||||||||

51 Julio Cabrera, O Cinema pensa- uma introdução à filosofia através dos filmes, tr. Ryta Vinagre, RJ, Rocco, (1999), 2006 (p.147)

52 S. Chatman, P. Duncan, (Ed.), Michelangelo Antonioni, A Investigação, tr. J.B.Boléo, Köln, Taschen, 2004. (p.103) 
Thomas, agora reduzido a um mero cidadão imerso na cidade grande e na sua solidão, claramente impotente diante das circunstâncias, aceita dialogar abertamente com o imaginário (personificado pelos artistas mímicos), chegando mesmo a nos surpreender quando desaparece no final do filme, maneira encontrada por Antonioni, para, emergir fulgurantemente como Autor ("É minha assinatura", disse ele) ) $^{53}$ em uma decisão que flerta com uma tradição brechtiniana, ao nos fazer relembrar que nós, espectadores, estávamos diante apenas de uma ficção, de uma imagem.

Se podemos dizer com Baudelaire que a Cidade é viva porque nela existe o homem e que sendo viva ela muda, ou ainda com Ferreira Gullar que o Homem está na Cidade, como a Cidade está no Homem, Antonioni, com uma sensibilidade perspicaz e distanciada, tece no filme os espaços efetivos e humanos a partir de dados narrativos tanto verbais (diálogos) quanto cenográficos (imagéticos), que podem ser associados a comportamentos sociais no meio urbano, inclusive os de hoje.

O filme não perdeu em nada sua atualidade nestes tempos de reinado absoluto do visual e de seus simulacros, moldados que somos pelos artefatos tecnológicos, e privilegia - se de uma reflexão pessoal de caráter ético e estético sobre o papel tanto do artista como da arte (a fotográfica como a cinematográfica) e de sua adequação para o exercício e a capacidade do olhar, além da distinção entre realidade e artifício. 